\title{
Alguns Problemas TeÓRICos da TraduÇão de LÍNGUAS ANTIGAS: REFLEXÕES ACERCA DAS DIFICULDADES DO TRADUTOR DO LATIM
}

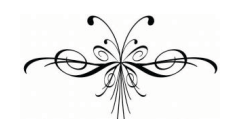

THAÍS FERNANDES

Resumo: Este breve artigo objetiva discutir algumas questões acerca de problemas da tradução do latim para línguas modernas. As reflexões apóiam-se nas leituras de três autores: Mounin (1975), Yebra (1994) e Berman (2007), e pretendem dar uma ideia de como a tradução de línguas antigas, em especial do latim, vem sendo discutida por alguns teóricos da tradução.

Palavras-chave: Teoria da Tradução; Tradução de línguas antigas; Tradução do latim

\begin{abstract}
This brief paper aims to discuss some questions related to the problems of translating from Latin to modern languages. My reflections rely on the readings of three authors: Mounin (1975), Yebra (1994) and Berman (2007), and intend to give an idea of how the translation from ancient languages, especially from Latin, has been discussed by some translation theorists.
\end{abstract}

Key-words: Translation Theory; translation from ancient languages; translation from Latin

$\mathrm{O}$ artigo proposto tem como objetivo discutir alguns problemas de tradução da língua latina para línguas modernas, especialmente as românicas ${ }^{1}$, suscitados pelas leituras de três autores: Mounin (1975), Yebra (1994) e Berman (2007). Pensando que o latim, assim como o grego, é uma língua morta ${ }^{2}$, sua tradução traz problemas distintos daqueles causados pela tradução de línguas modernas? Quais seriam alguns desses problemas? Como eles são discutidos por teóricos da tradução? São essas as questões que norteiam nosso trabalho e que, se buscamos responder, não o fazemos nem exaustiva nem definitivamente.

\footnotetext{
${ }^{1}$ As reflexões apresentadas aqui podem ser aplicadas a outras línguas. No entanto, por estarmos trabalhando somente com teóricos falantes de línguas românicas - Mounin e Berman são franceses; Yebra é espanhol -, focaremos nas dificuldades de tradução para as línguas desses autores e para o português, nossa língua materna.

${ }^{2}$ Como Lima (1995), entendemos que a expressão "língua morta" é uma figura que se refere à fala, mas que é muitas vezes generalizada e atribuída ao todo das línguas antigas. Tal expressão significa dizer apenas que não existe mais uma comunidade falante de tais línguas, por isso alguns autores, como o próprio Lima (1995), dão preferência à denominação "língua do passado", em detrimento de "língua morta".
} 


\section{Problemas TeÓRicos da Tradução de Línguas Antigas} de tradução:

De acordo com Jakobson (1995), podemos distinguir entre três espécies

1

A tradução intralingual ou reformulação (rewording) consiste na interpretação dos signos verbais por meio de outros signos da mesma língua.

A tradução interlingual ou tradução propriamente dita consiste na interpretação dos signos verbais por meio de alguma outra língua.

A tradução inter-semiótica ou transmutação consiste na interpretação dos signos verbais por meio de sistemas de signos não-verbais (JAKOBSON: 1995, p. 64-65).

Tratamos aqui, portanto, da tradução interlingual de uma língua antiga, o latim. Sabe-se que a língua latina deu origem às línguas românicas. Apesar do parentesco, as diferenças linguísticas, culturais e temporais entre a língua-mãe e suas filhas quase sempre fazem da tradução do idioma antigo para os modernos uma tarefa difícil para o tradutor.

Em Os problemas teóricos da tradução (1975), Georges Mounin reúne diversas teorias linguísticas sob o ponto de vista da tradução. $O$ autor ainda não vê a disciplina de Estudos da Tradução como independente, mas como ligada à linguística": "O nosso propósito até agora foi, portanto, fundamentar o direito que tem a tradução de figurar, como problema lingüístico digno de nota, num tratado de lingüística geral" (MOUNIN: 1975, p. 209). Ao mesmo tempo, Mounin (1975) afirma que não se deve encerrar a tradução dentro das fronteiras da linguística. Para entendermos os problemas da tradução do latim por ele colocados, faz-se necessária uma explanação de como entende o processo da tradução.

Segundo Mounin, o tradutor não deve conceber a tradução como uma mera operação linguística. Para ele, é impossível traduzir do latim somente através de sua gramática, sem um estudo da cultura latina. Define a tradução como "uma operação sobre fatos a um só tempo lingüísticos e culturais, mas cujos pontos de partida e de chegada são sempre lingüísticos" (ib.: 1975, p. 215). Retoma uma ideia que já estava nos tradutores greco-latinos, como Cícero: para traduzir o sentido não basta conhecer a língua, é necessário conhecer igualmente as coisas a que o texto se refere.

Os fatos culturais, que o tradutor não pode se furtar de conhecer, são explorados por Mounin na quinta parte de sua obra, intitulada "Civilizações múltiplas e tradução". Para reforçar a ideia de que não basta conhecer a gramática de uma língua para traduzi-la, o autor utiliza-se de conceitos matemáticos. Toda língua pode ser descrita como um sistema algébrico de relações e de correlações formais: a tradução, porém, não pode ser reduzida a "problemas de conversões algébricas formais, à passagem mecânica das fórmulas lingüísticas de um sistema (o russo, por exemplo) para as fórmulas lingüísticas de um outro sistema (o francês)" (ib.: 1975, p. 209). Isso porque há uma parte da língua que pode ser redutível a um sistema - a morfologia e a sintaxe - constituindo-se, as-

\footnotetext{
${ }^{3}$ Os Estudos da Tradução, como disciplina, foram estabelecidos por Holmes em The name and nature of Translation Studies (1988). Nesse texto, o autor caracteriza a disciplina como independente e empírica, com dois grandes objetivos: descrever o fenômeno da tradução como este se manifesta no nosso mundo, e estabelecer princípios gerais pelos quais este fenômeno pode ser prognosticado e explicado. Holmes ainda apresenta no mesmo texto um mapa dos principais ramos dos Estudos da Tradução.
} 
sim, em uma espécie de álgebra. No entanto, há outra parte - o léxico - que resiste a tal tratamento, e a estruturação formal e completa do mesmo, segundo o autor, ainda não existe. Explica que os próprios matemáticos sugerem que o limite estabelecido para o emprego da expressão sistema algébrico talvez seja de natureza lógica e que a matemática formal "é uma espécie de modelo vazio que só adquire a plenitude de sua validade quando verificado num mundo de significações" (ib.: 1975, p. 210), no mundo das verificações, no qual valores aritméticos (numéricos) são atribuídos aos signos e símbolos algébricos.

Mounin retoma as ideias de Bar-Hillel para as fórmulas anteriores e afirma que os modelos matemáticos que descrevem de modo abstrato os fenômenos da física devem apoiar-se em regras de correspondência com a realidade física concreta, pois a teoria em si mesma, despida das regras de correspondência, constitui um cálculo não-interpretado. Apenas com a união das regras de correspondência os termos teóricos adquirem uma significação e podem ser interpretados, tornando-se a linguagem teórica um meio de comunicação. Para Mounin "a lingüística descritiva moderna (a estrutural, a distribucional) obtém, ou poderia obter, fórmulas vazias, morfológicas e sintáticas desse mesmo tipo: pode-se dizer que elas refletem a estrutura das línguas como cálculos nãointerpretados" (ib.: 1975, p. 211). As fórmulas só se tornam significantes se lhes forem atribuídos valores concretos que as conectem ao mundo da experiência não-linguística. Assim, o léxico está para a linguística descritiva formal como a aritmética está para a álgebra. Nesse sentido, o autor demonstra ser possível ter duas leituras linguísticas isoladas de um texto: a das estruturas formais não-interpretadas e a das estruturas formais interpretadas por adição de valores semânticos. Dá cinco provas de que essas duas leituras seriam possíveis isoladamente: 1) línguas ainda insuficientemente decifradas; 2) aprendizagem de línguas estrangeiras - conhecimento praticamente completo do sistema morfológico e sintático, porém conhecimento insuficiente do vocabulário; 3 ) gírias; 4) jogos literários (ex.: Guimarães Rosa); 5) 'Eu sei francês' - pode-se deparar com um enunciado em que se consegue ler a estrutura formal, mas não há uma compreensão total da sentença por não se dominar os valores semânticos que a tornariam plenamente significante.

Em sua perspectiva, a tradução não pode permanecer no domínio do cálculo não-interpretado, e sim deve atribuir valores semânticos concretos às fórmulas vazias, pois o material e o produto final de qualquer tradução representam significações. Para ter acesso às significações o tradutor possui duas vias: a linguística e a etnográfica. $\mathrm{O}$ autor considera etnografia a "descrição completa da cultura total de uma determinada comunidade", entendendo como culturas "o conjunto de atividades e de instituições através das quais essa comunidade se manifesta" (ib.: 1975, p. 214). Baseado nessas definições, endossa a tese de Trager: "as relações entre a linguagem e cada um dos outros sistemas culturais conterão todas as significações das formas lingüísticas e constituirão a metalingüística dessa cultura" (MOUNIN, 1975, p. 214). Portanto, é necessário para o tradutor não apenas conhecer a língua a ser traduzida, mas também, e em igual medida, empreender uma etnografia da comunidade dessa mesma língua. Ele deve ser um tradutor-etnógrafo: "todo tradutor que, de mil maneiras empíricas, não se tenha transformado em etnógrafo da comunidade cuja língua traduz, é um tradutor incompleto" (MOUNIN, 1975, p. 219). 
Mas como o tradutor poderá ter acesso às significações por meio da etnografia no caso de uma língua como o latim? Como traduzir textos, nessa perspectiva, que foram produzidos por uma civilização não mais existente? A solução, segundo Mounin (1975, p. 221), está em "recorrer à história como descrição etnográfica do passado e particularmente como exploração etnográfica empreendida por uma civilização sobre o seu próprio passado". Assim, o tradutor passa de etnógrafo a filólogo. Afirma:

A filologia constitui uma pré-edição do texto a ser traduzido (no sentido de que ela traz para esse texto, em suas edições críticas, esclarecimentos quanto às informações não-explícitas por ele veiculadas), assim como uma pós-edição desse mesmo texto (no sentido de que ela acrescenta ao texto, original ou traduzido, notas que completam o acesso às significações) (MOUNIN, 1975, p. 221).

Filologia, na sua perspectiva, é uma etnografia não-orgânica do passado. E sem o conhecimento histórico-filológico, uma tradução poderia ter o seguinte resultado:

Suponhamos, diz Bréal, que para conhecer as magistraturas romanas só contamos com a etimologia e não com a história de termos como cônsules (os que tomam assento juntos), praetor (o que caminha na frente), tribunus (o homem da tribo), etc.: nós leríamos os textos latinos, sem entretanto, os compreender (ib.: 1975, p. 215).

Dentro dessa perspectiva, o autor declara que compreender o latim e traduzi-lo significa não só saber a língua latina, mas também conhecer a história do mundo latino, tarefa do tradutor-filólogo. A análise feita das operações executadas sob o rótulo de filologia permite concluir, mais uma vez, que as operações de tradução têm uma natureza dupla, e que nos textos referentes ao passado pode-se compreender os significantes sem compreender os significados.

Compreender os significantes sem compreender os significados é compreender tudo aquilo que é posto ao nosso alcance pelas relações formais que constituem o sistema lingüístico de uma língua, sua estrutura: lexicológica, morfológica, sintática - o que pode ser feito sem atingir os significados. A compreensão dos significados, somada à anterior, é acessível graças a uma outra operação: o conhecimento das relações arbitrárias, através do tempo, desta vez, dos mesmos signos com seus significados sucessivamente diferentes (ib., 1975, p. 224).

Yebra (1994) também explora problemas específicos da tradução de línguas antigas, especialmente do latim. Segundo o autor, a tradução de línguas clássicas se distingue da tradução de línguas modernas pelo seu valor como instrumento para a aprendizagem da língua que se traduz. Para ele, a prática da tradução deve ser o instrumento didático mais recorrente no ensino do latim, sem que seja concebida, ao mesmo tempo, como um simples instrumento, mas com um fim em si mesmo.

Para a aprendizagem da tradução, em geral, são necessárias naturaleza, enseñanza e ejercicio. Já o processo da tradução compreende duas fases: a compreensão e a expressão. Durante a leitura do original o texto começa a sofrer a influência do tradutor e a não ser mais o mesmo, o leitor realiza inconsciente- 
mente uma rápida análise semântica, que consta de uma análise léxicomorfológica e morfossintática, e ainda outra pragmática. Quando algum trecho não é imediatamente compreendido, o leitor necessita, com frequência, recorrer conscientemente a alguma ou a todas aquelas análises. A leitura de textos latinos demanda, em especial, o recurso a essas análises, as quais, para serem executadas, pedem um grande conhecimento do léxico, das estruturas gramaticais e da realidade linguística da língua por parte do leitor. E essas mesmas análises se desenvolvem na mente do tradutor habituado aos textos latinos com muita rapidez, e poucas vezes tornam-se conscientes. O erro em algumas dessas análises pode resultar numa compreensão inexata do texto latino, e, consequentemente, numa tradução equivocada. Por isso o tradutor deve ser, antes de tudo, um bom leitor. Pode-se perceber que esse autor não dá destaque, como Mounin (1975), ao conhecimento cultural e histórico do tradutor. Yebra dá preferência a uma discussão acerca de problemas linguísticos mais específicos suscitados pela tradução do latim como, por exemplo, o caráter sintético da língua.

De acordo com o autor, a ausência de artigos é uma das características que podem confundir o tradutor. Ele exemplifica a afirmação com a frase de César, de Guerra das Gálias: quod ex ea ciuitate Orgetorigis filiam in matrimonium duxerat. Duas traduções são linguisticamente possíveis: "Porque havia se casado com a filha de Orgetórix, que era daquele país" ou "Porque havia se casado com uma filha de Orgetórix, que era daquele país". Para traduzir esta frase corretamente, o tradutor precisa saber se Orgetórix tinha somente uma filha ou mais de uma. Por isso, Yebra afirma que é importante ler toda a obra antes de traduzir o trecho escolhido, pois ela mesma pode conter a resposta que o tradutor precisa. Tal afirmação nos faz perceber que Yebra acredita que se deve conhecer bem a obra que se está traduzindo, mas não inclui as informações históricas e culturais.

Outra fonte de dúvidas é a ambiguidade. Ela se dá em todas as línguas naturais, e, para o tradutor, é indiferente que ela proceda de uma polissemia (quando uma mesma palavra contém vários significados) ou do fenômeno da homonímia (quando duas ou mais palavras compartilham um mesmo significante); a dificuldade é a mesma. Encontrada uma ambiguidade, o tradutor pode conservá-la ou eliminá-la na tradução. Para decidir entre uma ou outra atitude, o tradutor deve: a) considerar se a ambiguidade do original é involuntária ou voluntária; b) se involuntária, perguntar-se se a ambiguidade enriquece a mensagem; c) avaliar se é claramente involuntária e causa algum tipo de confusão na leitura. Se a ambiguidade corresponder ao primeiro caso, o tradutor deve conservá-la. No segundo caso, o tradutor deve fazer o possível para mantê-la, para que o leitor possa decidir sobre a interpretação do trecho. Se a ambiguidade causa confusão, a atitude a ser adotada pelo tradutor é discutível. No caso da ambiguidade não poder ser reproduzida na língua de chegada, ele deve recorrer à nota de rodapé.

Sobre a tradução de poesia, Yebra explora dois problemas principais: 1) a reprodução das aliterações e 2) ser feita em verso ou em prosa. Sobre as aliterações, o tradutor deve reproduzi-las quando possível, fazendo uso dos recursos da língua de chegada. Já sobre o modo como se deve traduzir os versos, declara que a prosa possibilita mais fidelidade ao sentido, ao passo que o verso ao ritmo. Ao mesmo tempo, a prosa destrói o ritmo e o verso arruína a exatidão. Uma solução para a tradução dos hexâmetros clássicos seriam os 
versos livres. Porém, uma boa tradução poética em prosa é melhor que uma má tradução em verso. Entretanto, uma boa tradução em verso é melhor que uma boa tradução em prosa, e, ainda melhor que estas seria uma boa tradução em versos livres, sendo que o tradutor deve ser, antes de tudo, fiel ao conteúdo do original.

Por fim, Yebra conclui dizendo que "la regla de oro para toda traducción es, a mi juicio, decir todo lo que dice el original, no decir nada que el original no diga, y decirlo todo con la corrección y naturalidad que permita la lengua a la que se traduce" (1994, p. 344). A concepção de tradução de Yebra não está isenta de questionamentos por outras linhas teóricas, que concebem a prática da tradução de outra forma. Mas a presença desse pensador neste artigo deve-se a que é um dos poucos que expressou uma perspectiva da tradução do latim para nossos dias.

Antoine Berman, em A tradução e a letra ou o albergue do longínquo (2007), também trata de algumas questões da tradução do latim, embora não de modo específico. Entendemos que a intenção desse autor não é a de discutir tais questões, mas pensamos que dada a importância de sua obra para os Estudos da Tradução seria proveitoso observar o que tem a dizer a respeito do assunto. Berman critica as teorias tradicionais que concebem o ato de traduzir como um resgate estetizante do sentido e analisa algumas traduções "literais" que considera "grandes". Para ele, traduzir literalmente não significa aquilo que os espanhóis chamam de uma traducción servil, e sim a tradução do texto enquanto letra.

Antes de considerar o que o autor afirma sobre a tradução de línguas antigas, examinemos como entende o processo da tradução. Segundo diz, a essência última e definitiva desse processo é a tradução do texto enquanto letra. No entanto, a grande maioria das traduções se afasta dessa relação com a letra, ao mesmo tempo que as teorias da tradução condenam a chamada tradução palavra por palavra, ou o literalismo, justificando o afastamento. Tais teorias são, segundo Berman (2007), o "epifenômeno" de uma figura predominante na tradução ocidental. Essa se caracteriza por três traços: culturalmente falando é etnocêntrica; literariamente é hipertextual; e filosoficamente, platônica. Esses traços ocultam o que seria uma essência mais profunda da tradução que é ética, poética e pensante, que se definem em relação à letra, que é, por sua vez, seu espaço de jogo. Para chegar a esta essência mais profunda, Berman afirma que é necessário operar uma destruição da figura tradicional da tradução, precedida de uma análise do que há por destruir. Essa análise é denominada por ele analítica da tradução e critica a tradição etnocêntrica, hipertextual e platônica.

O autor se detém na tradução etnocêntrica e hipertextual (deixa de lado a questão do platonismo), que, segundo afirma, são as formas consideradas normais e normativas de tradução. Deve-se entender etnocêntrico como o que traz tudo à sua própria cultura, às suas normas e valores. Já hipertextual quer dizer qualquer texto concebido por uma transformação formal a partir de um texto já existente, seja por imitação, plágio, pastiche, paródia ou adaptação. Essas relações hipertextuais estão, do ponto de vista formal, muito próximas da tradução. A tradução etnocêntrica e hipertextual, segundo o autor, nasceu em Roma. Passado o período em que os autores latinos escreviam em grego, veio outro em que houve uma tradução massiva de textos gregos, através da anexação sistemá- 
tica de suas formas e termos, e que é o fundamento da literatura latina. "Mas os sentidos, como que capturados, trasladou-os à sua língua, como um direito de vencedor" e "Não traduzir uma palavra a partir de outra palavra, mas o sentido a partir do sentido" (BERMAN, 2007, p. 31): essas duas frases de São Jerônimo são citadas por Berman como a concepção da tradução que se tornou canônica no Ocidente.

O sentido, na perspectiva da tradução etnocêntrica e hipertextual, é considerado como um ser em si, que a tradução faz passar de uma língua a outra. A captação platônica do sentido é etnocêntrica, pois parte do pressuposto de que traduzir é apreender o sentido, separá-lo de sua letra; "a fidelidade ao sentido é obrigatoriamente uma infidelidade à letra" (ib.: 2007, p. 32). Nessa concepção, ser infiel à letra estrangeira significa ser fiel à sua própria letra. Por isso Berman alega que "a captação do sentido afirma sempre a primazia de uma língua" (2007, p. 33), pois o sentido da obra estrangeira deve submeter-se à língua de chegada. A primazia do sentido é a essência da tradução etnocêntrica.

Os dois princípios desse tipo de tradução apontados por Berman são: 1) a obra estrangeira deve ser traduzida de modo que não se "sinta" a tradução, e 2) essa deve ser feita de maneira que se tenha a impressão de que é dessa forma que o autor estrangeiro teria escrito se o tivesse feito na língua para a qual se traduz. Isto quer dizer que as marcas da língua de origem devem ser apagadas, ou pelo menos restringidas, de forma que o leitor não se choque com estranhamentos lexicais ou sintáticos. A língua da tradução, nesse caso, é normativa e objetiva causar no leitor de chegada a mesma impressão causada no leitor de origem. A consequência desses dois princípios é, segundo Berman, a intervenção massiva da literatura, pois, para que não se sinta a tradução como tradução, recorre-se a procedimentos literários, pois uma boa tradução, tem que ser escrita, em seu caso, em "bom francês", ou seja, em francês clássico, para que o leitor dessa língua não sinta estar lendo uma tradução. Esse é o ponto no qual a tradução etnocêntrica tornar-se-ia hipertextual.

Berman esboça, então, sua analítica da tradução. Ela diz respeito às forças deformadoras exercidas no domínio da prosa literária, que, "pelo fato de captar, condensar e mesclar todo o espaço polilingüístico de uma comunidade" (ib.: 2007, p. 46), acaba se caracterizando por uma certa informidade. Essa seria, segundo Berman, característica da grande prosa. Pelo fato de o prosador ter de lidar com uma grande massa linguística, ele acaba tendo um certo não-controle sobre sua escrita, e, "quanto mais o objetivo da prosa é total, tanto mais esse não-controle é manifesto [...]" (ib.: 2007, p. 47). Essa massa linguística traz questões específicas à tradução, tornando-se o principal problema dessa "respeitar a polilogia informe do romance e do ensaio" (ib.: 2007, p. 47).

As tendências deformadoras "formam um todo sistemático, cujo fim é a destruição, não menos sistemática, da letra dos originais, somente em benefício do 'sentido' e da 'bela forma"' (ib.: 2007, p. 48). A analítica parte do pressuposto de que a rejeição dessa "bela forma" e do sentido, principalmente pela automização da sintaxe, são a essência da prosa.

Estas tendências seriam treze. Segundo o autor, dizem respeito a toda tradução, quaisquer que sejam as línguas envolvidas, pelo menos no espaço ocidental: a racionalização; a clarificação; o alongamento; o enobrecimento; $o$ empobrecimento qualitativo; o empobrecimento quantitativo; a homogeneização; a destruição dos ritmos; a destruição das redes significantes subjacentes; 
a destruição dos sistematismos; a destruição ou a exotização das redes de linguagens vernaculares; a destruição das locuções; o apagamento das superposições de línguas. A tradução governada pelas forças e tendências apresentadas é, para Berman, fundamentalmente iconoclasta. Em lugar de a letra absorver o sentido, esse tipo de tradução faz com que das ruínas da letra deslocada brote um sentido "mais puro".

O autor analisa as traduções de Hölderlin, Chateaubriand e Klossowski. Destacamos o último tradutor, que traduziu dois dos mais importantes textos da Antiguidade: a Eneida de Virgílio e a Odisseia de Homero. Analisar a tradução de Klossowski, segundo Berman, não é somente analisar o como, mas também o porquê. Por um lado, afirma, as traduções de Klossowski de Eneida e Odisseia inspiraram duas das mais ambiciosas obras da literatura moderna, $A$ morte de Virgílio e Ulisses. Portanto, aqueles textos não apenas continuaram a ser influentes, mas a literatura moderna teve de "haurir" desta fonte. Por outro lado, há no século XX uma necessidade de reaproximação da origem, caracterizada por um grande movimento de retradução, que é, diz, sempre e em primeiro lugar um movimento histórico. Essa retradução moderna é, para Berman, uma memória repatriante. Estas obras foram sempre traduzidas livremente, adaptadas, imitadas. Porém, no século XIX, isso sofreu o que Berman chama de um duplo afundamento, causado, de um lado, pela ruptura crescente da literatura, e, de outro, pela crescente dominação da filologia sobre estes textos.

A filologia ${ }^{4}$, de acordo com Berman (2007), além de estabelecer e fixar os textos, também publica traduções críticas que procuram restaurar o sentido dos textos, sem ambição literária. Dessa forma, as outras traduções que não tinham bases "científicas" passaram a ser menosprezadas no sentido de que não situavam o leitor historicamente, não restituíam o sentido da obra como as edições filológicas, que passaram a dominar o acesso aos textos clássicos. Esse domínio da filologia, "se revelou fatal para nossa relação com as obras clássicas, porque produziu traduções fundamentalmente não legíveis. [...] Pois o conhecimento 'exato' de uma obra e de uma língua não habilita em absoluto à tradução e ao comentário" (2007, p. 112). O movimento de retradução do século XX tenta se aproveitar das contribuições positivas da filologia, porém em conformidade com as obras e com sua relação com a língua em que foram escritas.

A tradução de Klossowski levanta uma questão importante para a tradução do latim, abordada por Berman: a da ordem da frase. Pois tanto o francês, língua de Berman, quanto o português, nossa, são línguas analíticas, nas quais a ordem das palavras não é livre e obedece a certas regras. Sobre essa questão, o autor evoca Foucault, que diz: "a frase latina [...] pode obedecer a duas ordens: a da sintaxe, que as declinações tornam sensível; e a outra, puramente plástica, que uma ordem das palavras sempre livre, mas nunca gratuita, revela" (ib.: 2007, p. 115). Em decorrência desses fatos, o tradutor se vê diante de um impasse: de um lado, traduzir a frase na ordem em que as palavras aparecem resultaria um texto ininteligível na língua de chegada; de outro, colocar a frase numa ordem direta, canônica, deforma a letra do original, pois, como afirmou Fou-

\footnotetext{
${ }^{4}$ Apesar de não ser nossa intenção aqui discutir o conceito, chamamos a atenção do leitor para o fato de que Mounin e Berman entendem o papel da filologia de maneiras distintas. Para Mounin (1975), essa é importante para que o tradutor obtenha informações imprescindíveis acerca do texto que está traduzindo. Já Berman (2007) entende que o conhecimento filológico a respeito de uma obra não habilita ninguém a traduzi-la.
} 
cault, a ordem na frase latina é livre embora não gratuita. Berman (2007) encontra a solução para este problema na já citada tradução de Klossowski da Eneida, de Virgílio.

Para o autor, a tradução de Klossowski é uma das "grandes traduções literais" existentes. Para esse tradutor, o calco 5 era obviamente impossível. Por isso, o que fez foi ater-se à textura do original e sugerir o jogo de palavras latinas virgilianas. Sua tradução se afasta do original, mas dá a impressão de ser literal, distinguindo, segundo Berman (2007), dois planos: o primeiro é o modo geral da tradução, com uma forte latinização do francês; e o segundo é aquele no qual a latinização acontece sem ser um calco, que violentaria a língua de chegada. A solução está em reproduzir globalmente o jogo das rejeições, inversões e deslocamentos do latim, de modo que estes elementos "estranhos" aconteçam, mas em um lugar aceitável pela língua de chegada. Berman afirma que o ponto essencial é "procurar na frase francesa as malhas, os buracos por onde ela pode acolher - sem demasiada violência [...] - a estrutura da frase latina" (ib., p. 121), o que só será possível se o tradutor procurar o não-normatizado em sua língua.

As ideias dos três autores que apresentamos nos permitem pensar como podemos abordar o problema da tradução de língua antigas de formas diferentes. Mounin (1975) entende que o tradutor deve valer-se não só de conhecimentos linguísticos mas, em igual medida, de informações etnográficas do povo da língua da qual está traduzindo. Tratando-se de uma língua cuja comunidade falante não mais existe, caso do latim, ele deve recorrer à filologia para cumprir sua tarefa satisfatoriamente. Já Yebra (1994) prefere tratar de questões linguísticas mais específicas. Para tomar suas decisões, o tradutor deve sempre recorrer à intenção do autor do texto original e tentar preservá-la. Berman (2007), por sua vez, demonstra que o tradutor deve tentar reproduzir, sempre que possível, a textura do texto original. Quando isso não for possível, deve o tradutor tentar sugeri-la, aproximando-se da língua de partida, sem violentar a língua de chegada.

Entendemos que as línguas antigas suscitam problemas de tradução diferentes daqueles suscitados pelas línguas modernas. Ao traduzirmos línguas temporal e culturalmente distantes de nós, as quais não possuem mais uma comunidade de falantes, lidamos com questões específicas de tradução. Poucos são os autores que discutem e propõem uma teoria de tradução que abarque tais questões. Intentamos aqui mostrar e refletir sobre algumas teorias das quais o tradutor pode se valer para melhor exercer sua tarefa.

Thaís Fernandes

fernandes.tha@gmail.com

Universidade Federal de Santa Catarina

\footnotetext{
${ }^{5}$ Costa (1988), baseando-se em Vinay e Dalbernet (1958), define calco como aquilo que "traduz-se a forma estrangeira" por exemplo: "Mise-en-scène = Puesta en escena" (COSTA, 1988, p. 287).
} 


\section{Referências bibliográficas}

BERMAn, Antoine. A tradução e a letra ou o albergue do longínquo. Tradução, prefácio e notasMarie-Hélène Catherine Torres, Mauri Furlan, Andréia Guerini. Florianópolis/Rio de Janeiro: NUPLITT/7Letras, 2007.

Costa, Walter. "Tradução e ensino de línguas". In: BoHN, H.I; VANDRESEN, P. Tópicos em lingüística aplicada: o ensino de línguas estrangeiras. Florianópolis: Ed. da UFSC, 1988.

JAKOBSON, Roman. Lingüística e Comunicação. Tradução: Izidoro Blikstein e Jose Paulo Paes. São Paulo: Cultrix, 1995.

LimA, Alceu Dias. Uma estranha língua? Questões de linguagem e de método. São Paulo: Editora UNESP, 1995.

Mounin, Georges. Os problemas teóricos da tradução. Tradução Heloysa de Lima Dantas. São Paulo: Cultrix, 1975.

YEBRA, Valentin García. "La traducción del latín como problema". In: YEBRA, Valentín García. Traducción: historia y teoría. Madrid: Editorial Gredos, 1994. 